\title{
The risk of Non-Communicable Diseases after being Exposed to the Urban Flood; A Literature Review and Meta-Analysis
}

\author{
Renny Nurhasana ${ }^{1^{*}}$ and Risky Kusuma Hartono ${ }^{2}$ \\ ${ }^{1}$ Urban Studies Program, School of Strategic and Global Studies Universitas Indonesia, Central Jakarta, Indonesia, ${ }^{2}$ Sekolah \\ Tinggi Ilmu Kesehatan Indonesia Maju, South Jakarta, Indonesia
}

Received: 2021-07-06 Accepted: 2021-11-09

Keywords:

cardiovascular disease;

mental illness;

meta-analysis;

non-communicable

diseases(NCDs);

urban flooding

Correspondent email: rennynurhasana@ui.ac.id

\begin{abstract}
Risk mapping for the various types of non-communicable diseases (NCDs), which lead to the cause of death due to the impact of the urban flood, is rarely conducted. The study aimed to conduct a Systematic Literature Review (SLR) and meta-analysis of the risk of various NCDs after the community experienced the urban flood disaster. Methods: The data was taken from PubMed, ScienceDirect, Taylor and Francis, and ProQuest from June 2010 to June 2020 by searching for the words of flood and NCDs that only occurred in urban areas. This study refers to the guideline that is widely used to conduct meta-analysis research, namely PRISMA. The procedure was started by searching, screening, and validating the original articles through meta-analysis using R Studio. Twenty-six original articles were selected for SLR, and only two articles were not eligible for meta-analysis. Mental illness $(0.53,95 \% \mathrm{CI}, 0.33-0.68)$, heart problems $(0.39$, $95 \%$ CI $-0.11-0.73)$, and respiratory problems $(0.53,95 \%$ CI, 0.02-0.82) are the NCDs categories occurring after the community, predominantly female and the community aged $>40$ years, was exposed to the urban flood. This risk magnitude finding complements the previous studies that only did a literature review. The heterogeneous result $\left(\operatorname{tau}^{\wedge} 2 \mathrm{p}\right.$-value $\left.>0.05\right)$ and bias effects of publication (Egger test p-value $\left.>0.05\right)$ indicated that immediate assistance for victims is essential to prevent the onset of NCDs. Conclusion: Without early prevention and urban planning, the urban flood disaster can contribute to mental illness, heart problems, and respiratory problems.
\end{abstract}

2021 by the authors. Licensee Indonesian Jor

This article is an open access article distributed under the terms and conditions of the Creative Common

Attribution(CC BY NC) licensehttps://creativecommons.org/licenses/by-nc/4.0/.

\section{Introduction}

Urban populations are expanding rapidly worldwide, putting pressure on cities' resources and equal distribution. Combined with the current predictions of climate change impacts, this acutely urges urban areas to provide environments that support human health and well-being (van den Bosch \& Sang, 2017). In the ten years before 2011, flooding was the most frequent occurrence globally, accounting for nearly half of all disaster victims and nearly US\$ 185 billion in economic losses (Alderman, Turner, \& Tong, 2012).

As flood increases in urban areas, it causes diseases and contributes to about half of all deaths (Bich TH, Quang LN, Ha LTT, Hanh TTD, 2011; Fewtrell L, 2008; Ohl CA, 2000). According to the Center for Research on the Epidemiology of Disaster (CRED), flood is a natural disaster from the hydrological group due to the presence of water in normally dry areas divided into river floods, flash floods, and storm surges (Below R, Wirtz A, 2009; Doocy S, Daniels A, Murray $S, 2013)$. In urban areas, a flood occurs due to climate change and the increasing urbanization flows (Miller JD, 2017). The imbalance of development and land use also causes depletion in water catchment, which affects the intensity of standing water in urban areas (Pattison I, 2012; Wesli W, Sirojuzilam S, Matondang AR, 2013).

The total US population exposed to severe floods is 2.63.1 times higher than previously estimated (Wing OEJ, Bates
PD, Smith AM, Sampson CC, Johnson KA, Fargione J, 2018). In Korea, many floods occur in urban areas, and various cases of flood damage caused by heavy rains are primarily reported in urban areas (Kim Y Do, Tak YH, Park MH, 2020). In Indonesia, a flood makes up for $51 \%$ of the total disasters which are mostly reported in urban areas, and it occurs as the side-effect to the vehement land use (Amri MR, Yulianti G, Yunus R, Wiguna S, Adi AW, Ichwana AN, Randongkir RE, 2016; Wesli W, Sirojuzilam S, Matondang $A R, 2013)$. On average, a flood occurs at the height of 0.3 1.5 meters, duration of 3 - 10 hours, and covers up to 200 ha of an area (Mazzoleni et al., 2014; Sofia, Roder, Dalla Fontana, \& Tarolli, 2017).

The impact of flood exposure is not only property damage and economic consequence, but it also results in the risk of diseases (Lowe D, Ebi KL, 2013). Most studies have reported many health problems caused by floods, including infectious diseases such as cryptosporidiosis, leptospirosis, and campylobacter infection (Lowe D, Ebi KL, 2013; Rossati A, 2017; Walker JT, 2018). In the long period, several studies have stated that the health facilities utilisation for skin infection, acute respiratory infection, and diarrhoea from infectious diseases groups has vastly increased due to the effect of the flood (Saulnier DD, Brolin Ribacke K, 2017; Saulnier DD, Hanson C, Ir P, Mölsted Alvesson H, 2018). However, a few studies also report the risk of having non- 
communicable diseases (NCDs) after being exposed to the flood.

NCDs have slow manifestations, incurability, and inclination of premature deaths (Wei et al., 2020; WHO, 2011). Loss due to NCDs is estimated to reduce productivity and quality of life and increase mortality compared to the loss due to infectious diseases (Stanaway JD, Afshin A, Gakidou E, Lim SS, Abate D, Abate KH, Abbafati C, Abbasi $\mathrm{N}, 2018$ ). For example, studies in the last six years reported mental illness as a type of NCDs due to flood (Graham $\mathrm{H}$, White P, Cotton J, 2019; Jahan S, 2015; Lieberman-Cribbin W, Liu B, Schneider S, Schwartz R, 2017).

Research in France stated that neuroticism is one of the briskest side-effects on flood victims (Weiss K, 2020). The risk of asthma is also among the list (Jimenez, Collins, \& Grineski, 2013). Japan Diabetes Society prepared the prevention of hypoglycemia as the onset of diabetes in flood victims (Satoh J, Yokono K, Ando R, Asakura T, Hanzawa K, Ishigaki Y, Kadowaki T, Kasuga M, Katagiri H, 2019). In addition, although it is not significant, there is a potential for flood victims to have cancer (Wolfram F, 2019). In Thailand, the traumatic effects suffered by flood victims potentially increase blood pressure as a symptom of cardiovascular disease (Yoda, Yokoyama, Suzuki, \& Hirao, 2017). However, the mapping of NCDs categories is still moderate, especially in urban areas (Ryan B, Franklin RC, Burkle FM, Aitken P, Smith E, Watt K, 2015).

Therefore, the purpose of this study is to conduct a systematic literature review and meta-analysis of the risk of NCDs categories after being exposed to the urban flood disaster. There are two research questions in this study. First, what is evidence of the types of NCDs after people in urban areas are exposed to floods? Second, what is the magnitude probability for flood victims who will suffer from any of the NCDs? The result is expected to map NCDs' risks by their categories due to the flood in urban areas. This study can also be utilised by the central governments, local governments, and urban planning experts to develop a prevention program for urban floods. The prevention program is crucial so that there is no loss due to NCDs, people are not susceptible to NCDs due to flood, and the community's quality of life improves.

\section{Methods}

This study refers to the guideline widely used to conduct meta-analysis research, namely PRISMA statement (Equator Network, 2019). The study was conducted based on the guideline by searching the original articles, screening, and validating the selected papers through meta-analysis. This activity was executed during July 2020 by two primary researchers who have expertise in urban planning and NCD prevention as the authors of this study and four research assistants from bachelor of Public Health backgrounds and Bachelor of Geography. They helped to search the original articles from the online International digital libraries. The research also had been registered as a protocol in PROSPERO with ID 199883 on 20 July 2020. PROSPERO is the international database of registered systematic reviews for human or animal studies to ensure that the researchers review new and prospective issues.

The study's inclusion criteria were limited to the primary or original articles published in the last ten years, from June 2010 to June 2020. Original articles with a cohort, case- control, or cross-sectional study design were included in this study. The urban area was also a study inclusion. The association or relationship in this study is only to focus on the risk of having NCDs after being exposed to the urban flood.

The exclusion criteria were the risk of infectious diseases and the risk of injury after being exposed to the urban flood because all types of injuries are different disease categories with contagious diseases and NCDs (Stanaway JD, Afshin A, Gakidou E, Lim SS, Abate D, Abate KH, Abbafati C, Abbasi $\mathrm{N}, 2018$ ). Original articles which were not written in English were not analysed further. Articles published above ten years were no longer identified in this study.

The sample of the study was urban communities, especially for the victims of the urban flood. The characteristics of urban areas are seen from the regions close to the industrial, residential, and public services (Natgeo, 2018). Determining the urban factors was done by viewing the research location on either the title, the abstract, or the method of the original article. The characteristics of the research location were further assessed by viewing the similarities with the urban features from Google data. We excluded the original article if there was no explanation about the research location in the article. The original article reported at the country level, especially from high-income countries, as the study location represented a condition in an urban area. This study assessed the characteristics of the sample, including the means of the victims of urban floods and the proportion of female gender, city, country, and continent.

The study's outcome is the risk of various categories of NCDs as the diseases with slow manifestations, incurability, and the inclination of premature deaths (Wei et al., 2020; WHO, 2011). The Global Burden Disease (GBD) Report stated that flood victims are prone to the NCDs group categories of cancer, heart problems, stroke, respiratory problems, mental illness, neurological illness, diabetes, musculoskeletal illness, and other diseases (Satoh J, Yokono K, Ando R, Asakura T, Hanzawa K, Ishigaki Y, Kadowaki T, Kasuga M, Katagiri H, 2019; Stanaway JD, Afshin A, Gakidou E, Lim SS, Abate D, Abate KH, Abbafati C, Abbasi N, 2018; Weiss K, 2020; Wolfram F, 2019; Yoda et al., 2017). The measurement risk of having NCDs was assessed from the value of the association, including Odds Ratio (OR) of the beta coefficient or coefficient correlation from statistical analysis of each selected original article. Then, this study recalculated OR with a natural $\log$ formula to get beta coefficient when there was no information about the $2 \times 2$ table in the OR calculation as the requirement calculation of meta-analysis.

Original articles related to the urban flood and the risk of having NCDs were identified from 4 online international digital libraries. PubMed, Science Direct, Taylor and Francis, and ProQuest are well-known and reputable for health databases of journals and their bibliometrics that are easy to replicate by other investigators. All digital libraries were accessed from the Indonesian government national library, which is subscribed to the journal database.

First, accessing PubMed was done by visiting the address https://pubmed.ncbi.nlm.nih.gov/, entering the keywords into the search engine, checking the mark of the article type, and limiting the last ten years of publication (2010-2020). Second, accessing ScienceDirect was done by visiting the 
address https://sciencedirect.com or through the login at the "National Library of the Republic of Indonesia" website, choosing ScienceDirect, and doing the same as the PubMed website for finding the articles. Third, accessing Taylor and Francis was done by visiting address https:// taylorandfrancis.com/, selecting only article types, and finding the articles. Fifth, accessing ProQuest was done by logging in to the "National Library of the Republic of Indonesia" website, choosing the ProQuest link, and doing the same as the PubMed and ScienceDirect websites for finding the articles.

The strategy of searching the original articles was done by combining "Flood and Non-Communicable Disease" keywords. This study explored into more details with more specific keywords, namely "Flood and mental illness", "Flood and neurological illness", "Flood and diabetes", "Flood and Hypertension", "Flood and Cancer", "Flood and Cardiovascular", "Flood and stroke", "Flood and asthma".

The selection process and the evaluation of the article were started by typing the keywords according to the strategy. First, the evaluation strategy of the article was done by identifying the title in each searching result and ensuring that the type of article was the original article by reading the method section in the abstract. Every title of the article that matched the criteria was downloaded. It was stored in one folder with the categories of PubMed, Science Direct, Taylor and Francis, and ProQuest folders. The second step was removing the duplicated articles in each folder. Duplicated articles that appeared multiple times during a keyword search were not reused. Third, further screening the inclusion criteria and ensuring the articles were in line with the requirements in this study. The next step was conducting a review of the results of the article. This stage was done by ensuring the measurement of the association, which was reported in the article. The fifth step is compiling the selected articles and describing them in a table form. The last is to make a listing table containing the country names and the number of countries from the chosen articles to create a geographical map using QGis Software.

Data analysis was done by giving a narrative in table 1. Meta-analysis was displayed in the figure. The statistical analysis of meta-analysis for this study was the effect of heterogeneity by using Q statistics, I-statistics, visual effect by using forest plot, and publication bias by drawing the funnel plot. The result is significant if there is no effect of heterogeneity and publication bias in the selected articles. All analyses were performed using $\mathrm{R}$ Studio software version 4.2.

\section{Result and Discussion}

The literature search results that identified articles of risk of having NCD after being exposed to the urban flood are displayed in figure 1 . After reading the abstracts, there were 150 excluded articles in the screening step because 23 articles are not reported in urban areas, 70 are not originally peerreviewed, and 25 are qualitative study articles. The other 17 articles have the association measurement, but they do not focus on the association of urban floods and the risk of having NCDs, and 15 articles are not highlighting urban floods. There were 52 articles related to flood exposure and NCDs, but 13 did not report the association test.

This study selected and included twenty-six articles based on the inclusion and exclusion criteria for further evaluation as Systematic Literature Review. Based on the classification of each disease, 21 articles discussed mental disorders, three articles discussed heart disease, and three articles discussed respiratory disease. Among all these articles, there was an article in which two kinds of conditions, including mental disorders and respiratory disease, by Alderman et al. (Alderman, Turner, \& Tong, 2013).

Two articles reported on cases of schizophrenia and anxiety after exposure to urban floods (Maclean, Popovici, \& French, 2016; Wei et al., 2020). The articles were excluded for meta-analysis because these articles do not have other comparison articles with the same diseases. Finally, 24 articles were included for Meta-Analysis, comprising 18 articles reporting on mental illness, three articles reporting on heart problems, two articles reporting on respiratory problems, and an article reporting on mental illness and respiratory problems.

\section{Systematic Review}

Table 1 displays the characteristics of the selected articles for systematic review analysis. The categories of NCD that are significantly associated with the victims of urban flood are mental illness (Post-Traumatic Stress Disorder or PTSD, depression, anxiety, and schizophrenia), heart problems (cardiovascular disease, hypertension, and heart failure), and respiratory problems such as asthma. Most articles use a cross-sectional design with a short follow-up year (less than five years) of 17 articles. All articles with a follow-up $>5$ years reported the NCD types from mental illness. The results of this review indicate that mental illness due to flood exposure occurs both in the short and long term. Fourteen articles reported short term or less than five years cases of having a mental illness after being exposed to the urban flood, six articles reported long term or equal or more than five years cases of having a mental illness, and only 1 article did not report the time span of suffering from mental illness.

The selected articles reported various sample sizes ranging from small samples to national data. The age of respondents who became the victims of a flood is $\geq 40$ years old on average. Over $50 \%$, the proportion of female respondents was found in 19 articles. In the category of mental illness, the smallest coefficient comes from the study of Wei et al. on schizophrenia at 0.01, and the largest is PTSD at 0.91 in three studies.

Most of the articles do not explain the modifiable factors such as unhealthy lifestyle behaviors as the control variables of having NCDs because the selected articles focus on urban flood victims. However, almost all articles reporting age and all of the articles reporting gender as the unmodifiable factors of NCDs have been reviewed in this study.

Most countries that report the most risk of getting NCD after being exposed to urban flooding are developed countries (figure 2). They are America (23\%), China (12\%), Australia (15\%), and Japan. Countries in the Asian continent are the countries that report the most articles on the risk of having NCD after being exposed to urban floods.

\section{Meta-Analysis}

There are 19 articles that reported the association between flood exposure and the risk of mental illness from the PTSD category and depression (figure 3 ). The heterogeneity test results in the random effect model show that the heterogeneity test with $\operatorname{tau}^{\wedge} 2$ is $0.273,0.208,0.243$, and all of 


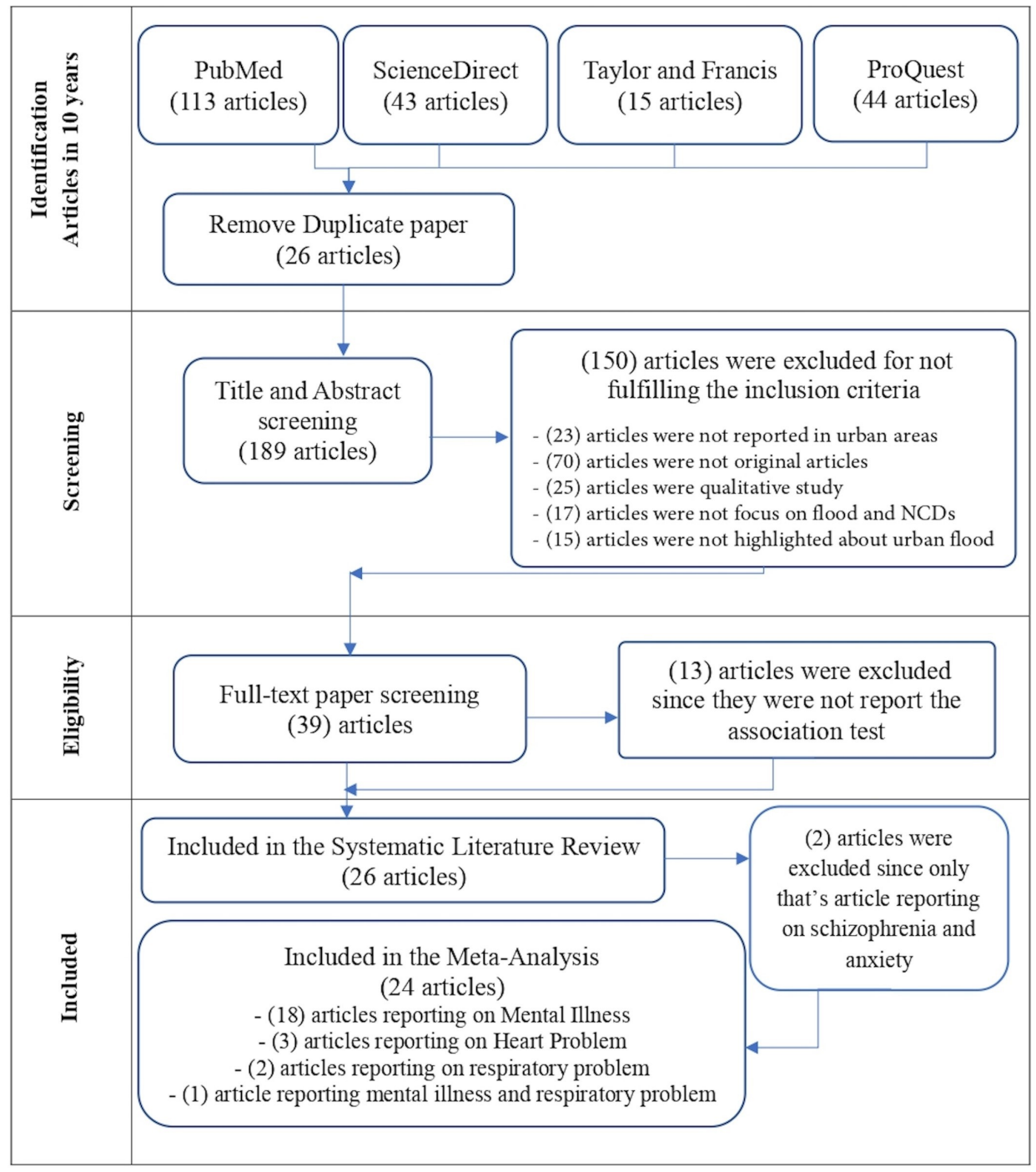

Figure 1. PRISMA Flow Diagram of Inclusion Criteria for Meta-Analysis

\section{Reported ariticles of NCD association after exposed with urban flood}

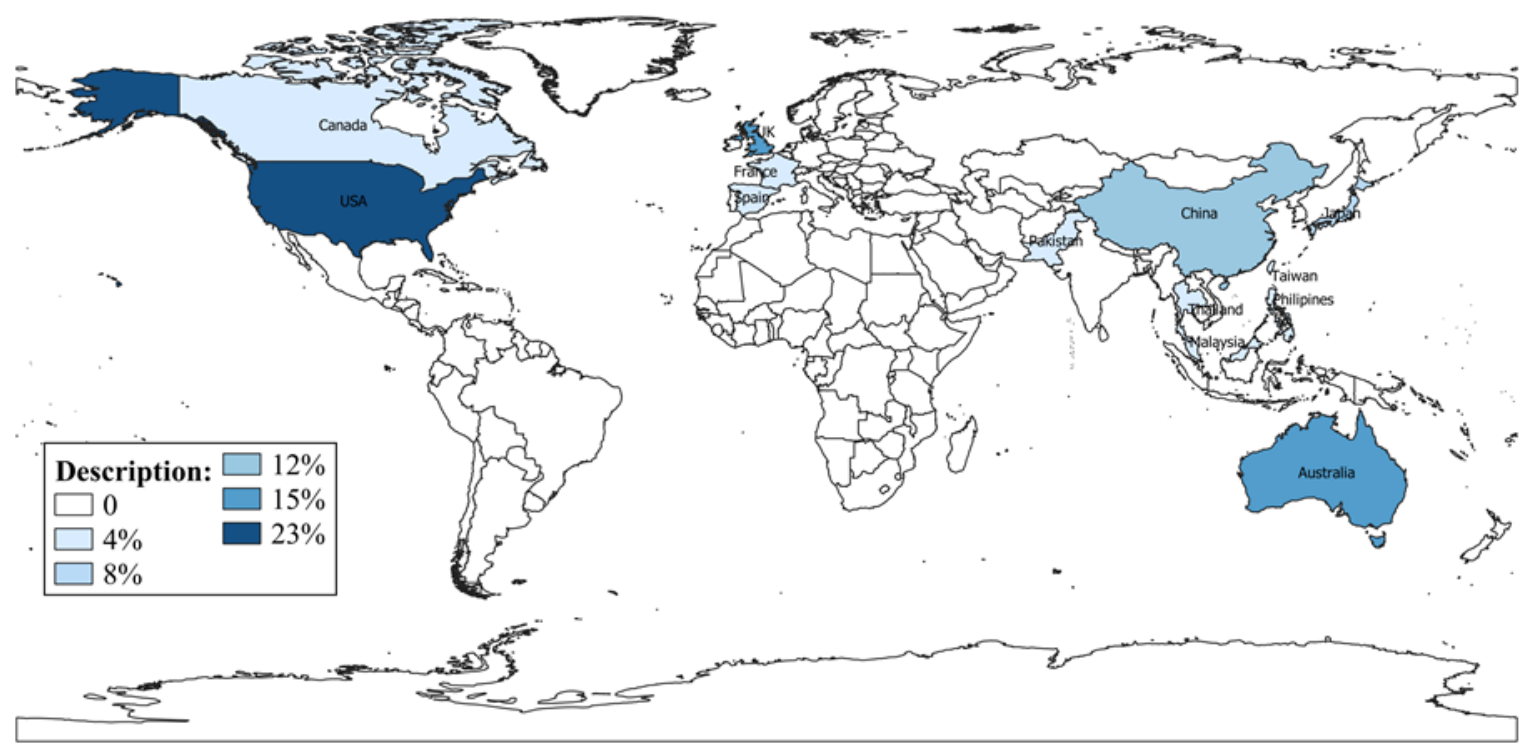

Figure 2. Map Distribution of Reported Articles of NCD Association After Exposed with Urban Flood by Countries

Notes: Forrest Plot mental illness (PTSD and depression) is located at top, heart problem (middle), and respiratory problem (at the bottom) 


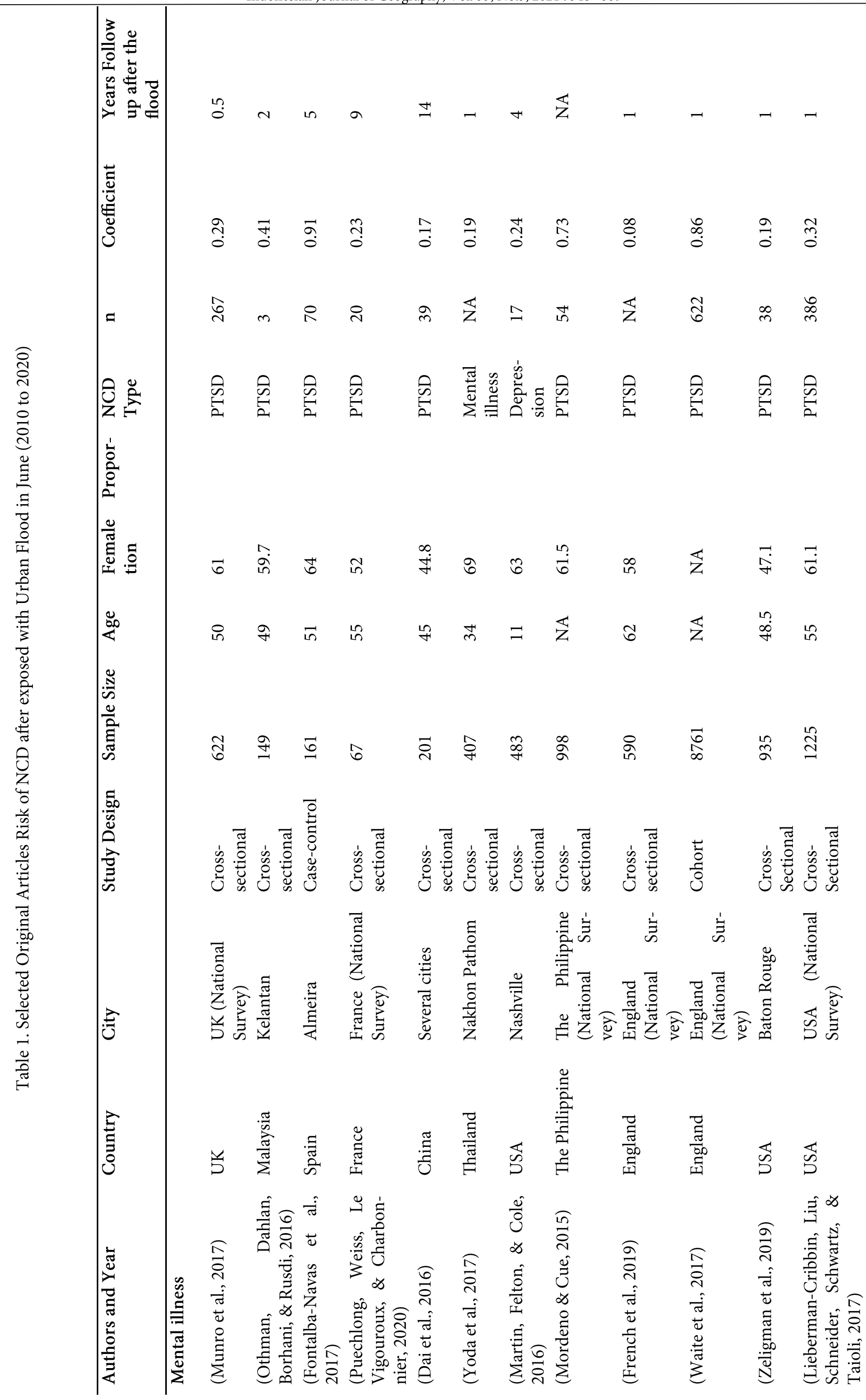




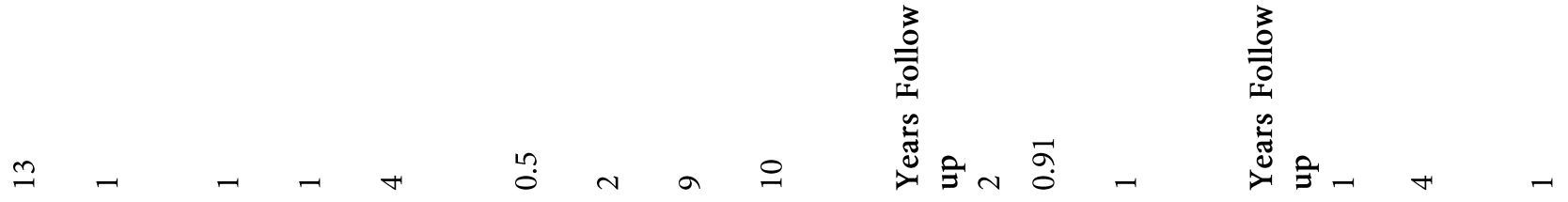

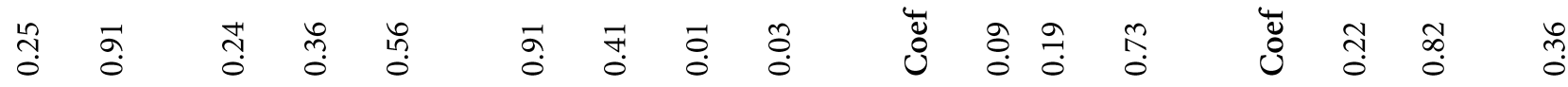

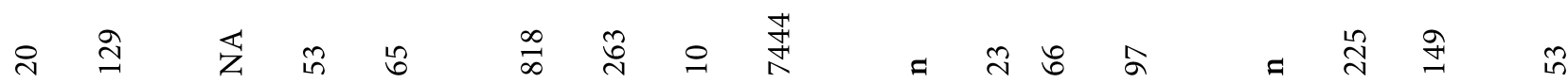

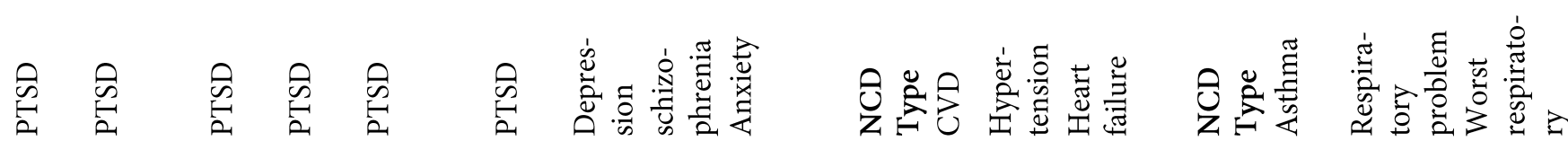

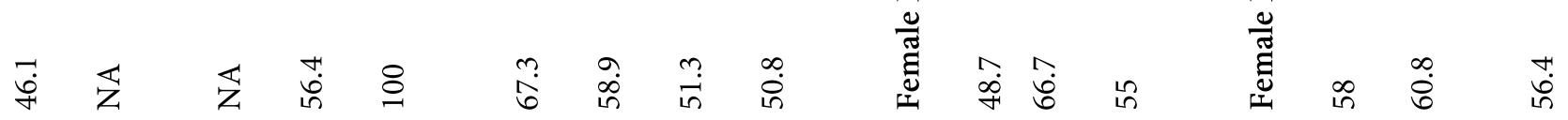

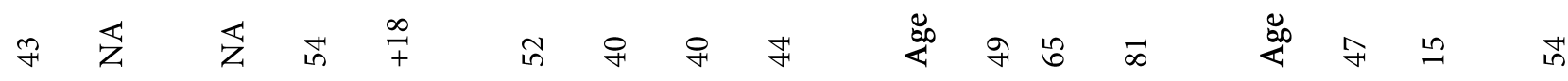

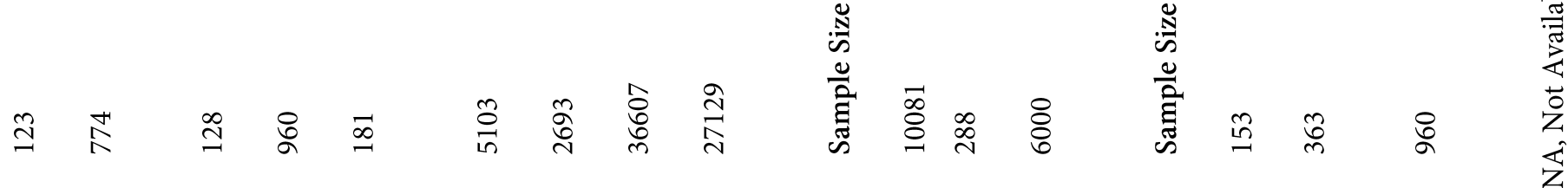

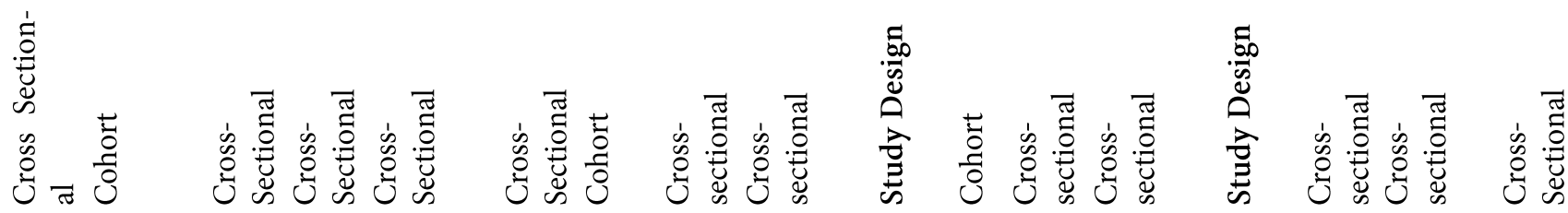

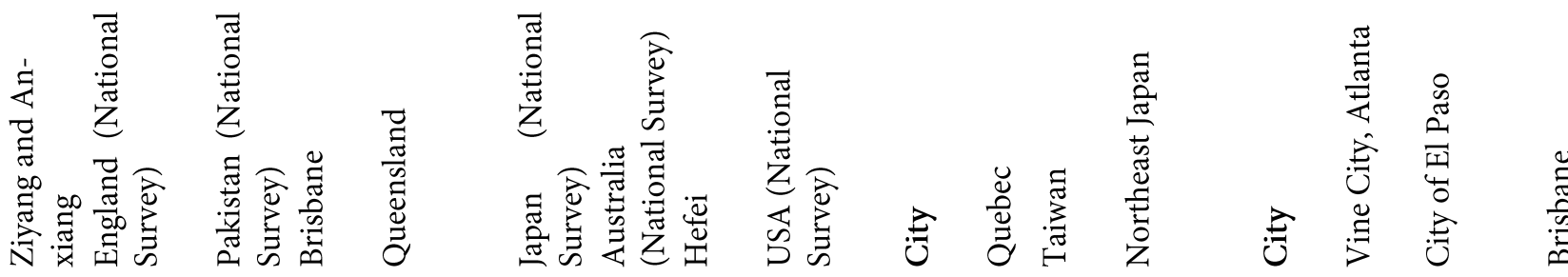

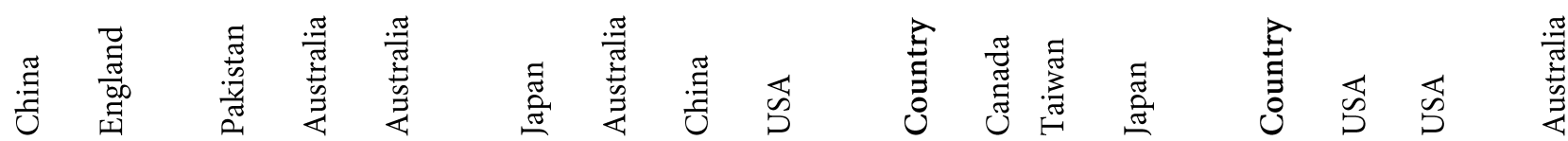

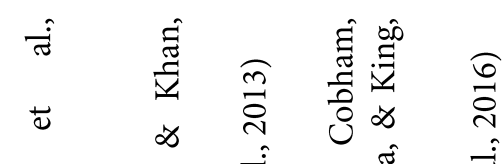




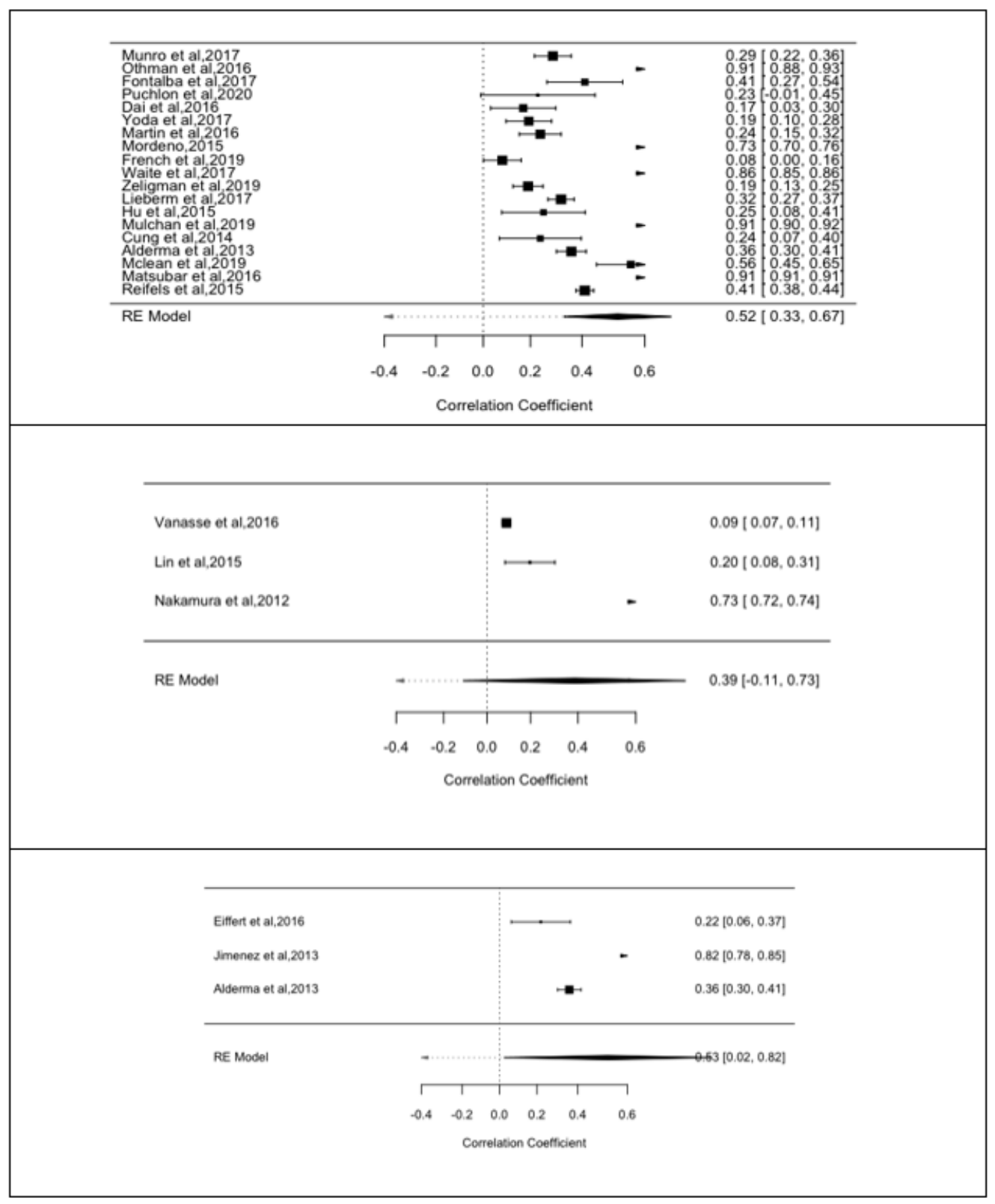

Figure 3. Forest Plot between Urban Flood Exposure and Risk of NCD

the $\mathrm{Q}$ values have $\mathrm{p}<0.0001$. This indicates a heterogeneous association between flood exposure and the risk of mental illness (PTSD and depression), heart problems, and respiratory problems, respectively.

Total heterogeneity is divided by the variability $\left(I^{\wedge} 2\right)$ flood exposure and the risk of mental illness (PTSD or depression). The risk of heart problems and respiratory problems is $99.65 \%, 99.88 \% 98.90 \%$, respectively. This figure describes the high level of heterogeneity in the association between urban flood exposure and the risk of having NCD. The heterogeneity of the association indicates other control variables with strong influences play an important role in the onset of PTSD.

An article shows an insignificant association between urban flood exposure and PTSD, but the others are significant (figure 3). The result of the study by using small samples produces the greatest coefficient value. They are 0.91 (95\% CI $=0.88-0.93)$ in mental illness, 0.73 (95\% CI=0.72$0.74)$ in heart problems, and 0.82 (95\% CI $0.78-0.85)$ in respiratory problem. The final correlation is $0.53(95 \%$
$\mathrm{CI}=0.33-0.68)$ in mental illness and 0.53 (95\% $\mathrm{CI}=0.02-0.82)$ in respiratory problems, which indicates a strong association (high) between flood and risk mental illness and respiratory problems. The final correlation of heart problems is not significant at 0.39 (95\% CI=-0.11-0.73). The results of publication analysis bias using the funnel plot show that all articles can be biased (figure 4). All egger regression tests show at $p>0.05$, which indicates the possibility of biased results.

\section{Discussion}

Based on the results of this study, there are still not many articles on the topics of floods and the risk of specific NCDs in urban areas. It shows from only 19 articles about mental illness and three articles about heart problems and respiratory problems within the last ten years. However, the articles that discuss flood and NCDs in urban areas without reporting the association have been reported earlier (Cheng M, Wen S, Jian Zhou H, Lian-fang B, Li J, 2013; Ryan BJ, Franklin RC, Burkle FM, Smith EC, Aitken P, 2019; Wolfram $F, 2019)$. The other articles discuss the association of floods 


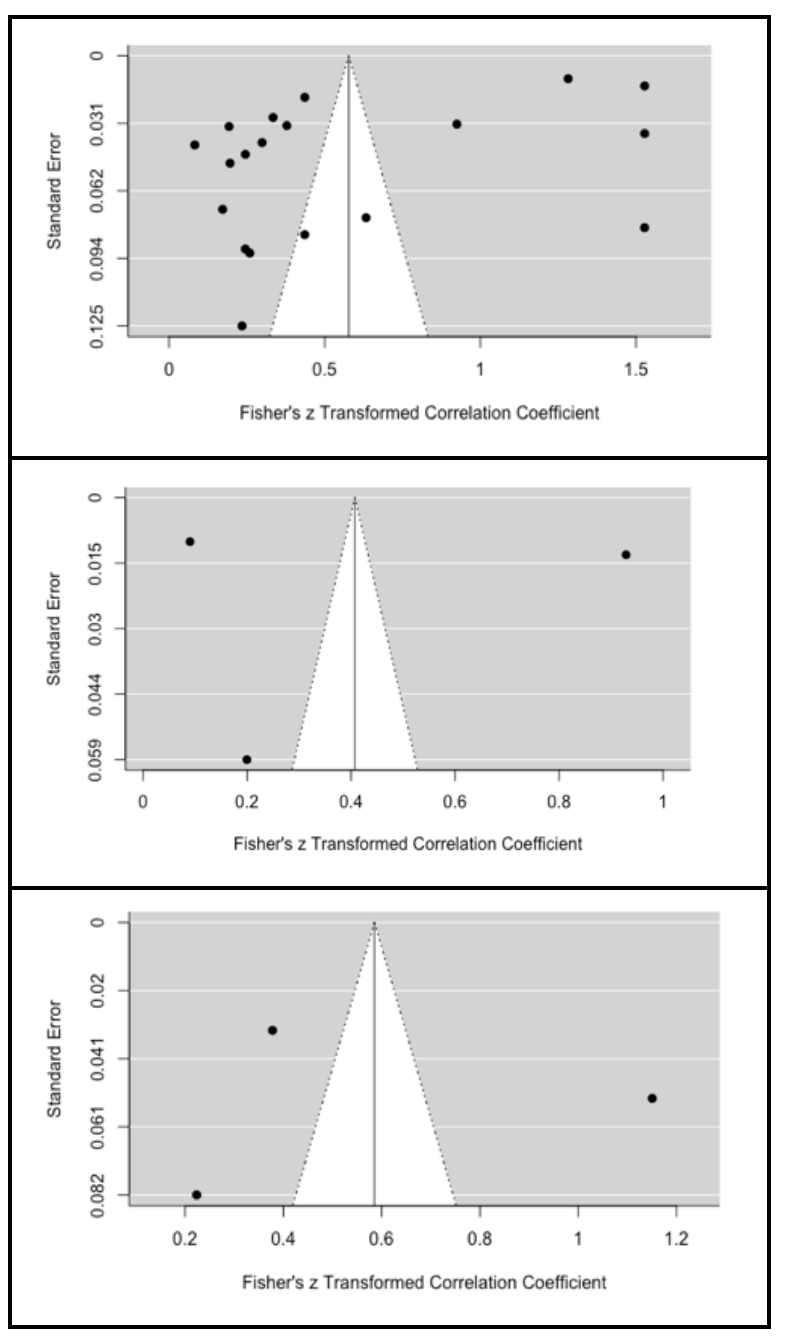

Figure 4. Funnel Plot of Urban Flood Exposure and Risk of having NCD

with the risk of infectious diseases (Lowe D, Ebi KL, 2013; Rossati A, 2017; Walker JT, 2018). Theoretically, it can be proven that the effects of flood give heavy losses to the victims, including property damage, various diseases (infectious diseases and NCDs), and deaths (Lowe D, Ebi KL, 2013; Rossati A, 2017; Saulnier DD, Brolin Ribacke K, 2017; Saulnier DD, Hanson C, Ir P, Mölsted Alvesson H, 2018; Walker JT, 2018).

\section{Mental Illness}

One of the fastest effects which the flood victims suffer is the traumatic due to the high levels of neuroticism and catastrophising and the leading causes of the emergence of PTSD (Weiss K, 2020). Flood victims can be at high risk of experiencing PTSD after months (Fontalba-Navas et al., 2017). This key finding is supported by other studies' results (Graham H, White P, Cotton J, 2019; Jahan S, 2015; Lieberman-Cribbin W, Liu B, Schneider S, Schwartz R, 2017).

In the long period, PTSD also appears after 13 years of flooding (Hu S, Tan H, Cofie R, Zhou J, Yang T, Tang X, 2015). The traumatic effects could reappear, especially to those who have experienced two times or more becoming flood victims (Husky MM, Alvarez V, Tapia G, Oprescu F, Navarro-mateu F, Kovess-masfety V, Ea LDP, 2020). This explanation is in line with the results of this study which state that the risk of mental illness such as PTSD, anxiety, or depression can occur short or long periods after floods. This study has also been proven by previous systematic review studies (Fernandez A, Black J, Jones M, Wilson L, SalvadorCarulla L, Astell-Burt T, 2015; Huang P, Tan H, Liu A, Feng $S, 2010)$. In addition, reappearing of PTSD has been proved to increase the risk of having hypertension, hyperlipidemia, obesity, cardiovascular disease, and stroke through the effects of catecholamines in the heart, vasculature, and platelet function (Coughlin, 2011).

The sociodemographic characteristics show that the vulnerable flood victims commonly comprise women and the community aged $\geq 40$ years. Especially for stress and anxiety, women are more receptive to those responses due to low social support and emotional instability (Dai W, Kaminga AC, Tan H, Wang J, Lai Z, Wu X, 2017). Characteristics of people aged 7-14 years are more susceptible to PTSD because the possibility for children to develop PTSD increases in a family with PTSD's parents (Li X, Huang X, Tan H, Liu A, Zhou J, 2010). This group should receive significant social support related to the prevention and recovery from PTSD (Dai W, Chen L, Tan H, Wang J, Lai Z, Kaminga AC, Li Y, 2016).

\section{Heart Problems}

There is one article found in this study that reported the association between flood victim and CVD (Nagayoshi Y, Yumoto S, Sakaguchi K, Shudo C, Takino S, Hashiyama M, Kai Y, Kuroda Y, Kawano H, 2015). This evidence was also found in another systematic review article (Ryan B, Franklin RC, Burkle FM, Aitken P, Smith E, Watt K, 2015). The traumatic effects suffered by flood victims in the long term can increase stress levels, blood pressure, and possible manifestations of NCD (Yoda et al., 2017). Hypertension is more disposed to be suffered by pregnant women after becoming the flood victims (Laplante DP, Hart KJ, O'Hara MW, Brunet A, 2018). This happens because the body of pregnant women responds too much to the adverse effects of being a flood victim, especially for those who do not receive adequate social assistance and trauma healing for the flood victims (Paterson DL, Wright $\mathrm{H}, 2018$ ).

The results of this study showed that there is an association between the risks of developing heart problems after being exposed to urban flooding. It happens because heart problems cause stress and prolonged anxiety due to the influence of the production of the cortisol hormone (Birkett MA, 2011; O'Donovan A, Hughes BM, Slavich GM, Lynch L, Cronin M-T, O'Farrelly C, 2010). After meta-analysis, the result is not significant. The main factor is the immediate help for flood victims so that stress, anxiety, and depression do not occur in urban flood victims (Dai W, Chen L, Tan H, Wang J, Lai Z, Kaminga AC, Li Y, 2016).

\section{Respiratory Problems}

Almost half of the flood victims potentially have respiratory problems after being exposed to the flood (Saulnier DD, Brolin Ribacke K, 2017; Saulnier DD, Hanson C, Ir P, Mölsted Alvesson H, 2018). The risk of asthma is the most frequent outcome during the review of the articles (Jimenez et al., 2013). This result is supported by the result of meta-analysis, which has a significant risk of respiratory problems due to the flood. Humid buildings and the appearance of fungi cause the risk of respiratory problems after being exposed to the flood (Eiffert et al., 2016). This 
condition is the worst for the socio-economic scheme, particularly for the poor. A continuous assessment of the poor community affected by floods is essential to finding the cause of respiratory problems and preventing the worsening (Alderman et al., 2013).

\section{Other NCDs}

There is not much evidence for increased blood glucose and diabetes as the side-effects of floods (Bich TH, Quang LN, Ha LTT, Hanh TTD, 2011). However, the flood victim may get hypoglycemia (Satoh J, Yokono K, Ando R, Asakura T, Hanzawa K, Ishigaki Y, Kadowaki T, Kasuga M, Katagiri $H, 2019)$. Other research stated that someone diagnosed with diabetes or hypertension was impacted by flood; their diseases worsened (Bich TH, Quang LN, Ha LTT, Hanh TTD, 2011). As well as diabetes, there is no evidence for the risk of having cancer after being exposed to the flood (Ryan B, Franklin RC, Burkle FM, Aitken P, Smith E, Watt K, 2015). An article reported the cancer case with the flood, but there are no association statistics (Wolfram F, 2019).

\section{Policy Option}

Several developed countries have implemented technology such as flood Disaster Risk Reduction (DRR) to prevent and detect flood risk (McCallum et al., 2016). For instance, in Spain, The Government used GIS systems to represent flood-affected areas and the rainfall intensity compared to historical hydrological data (Fontalba-Navas et al., 2017). The government analysed sociodemographic factors, such as the material losses, the predictor for PTSD in flood-affected populations to develop effective plans to tackle the burden of similar natural disasters in the future (Fontalba -Navas et al., 2017). Not only in developed countries, a developing country such as Vietnam already has a national disaster database to assess the risk of regional flooding (Luu C, von Meding J, 2019). It can be said that many flood cases that are at risk of being affected by NCDs are reported to come from developed countries. However, most of the developed countries are ready to anticipate the danger of flooding.

Post Disaster Management in Australia, a program called Allied Psychological Services (ATAPS), gives specific primary services post-disasters, including floods (Reifels et al., 2015). Provision of insurance benefits for flood victims helping to reduce the level of stress and anxiety is only available in developed countries (Hanger S, Linnerooth-Bayer J, Surminski S, Nenciu-Posner C, Lorant A, Ionescu R, 2018; Mulchandani et al., 2019; Vanasse et al., 2016).

In Ghana, the government anticipates flooding by protecting waterways; monitoring and controlling development in flood-prone areas; and managing education programs against flood (Poku-boansi M, Amoako C, Owusuansah JK, 2020). In Jakarta, Indonesia, Decentralization compels the Local Government to use public funds to develop flood mitigation, coordinate with disaster management at the provincial level (SATKORLAK), the district level (SATLAK), and the sub-district level (SATGOS/ POSKO) supported by the Ministry of Public Works (PU), and cooperate with the Kelurahan (Ward) and KORAMIL (Military District Command) to improve risk warnings, evacuations, and resettlement (Van Voorst, 2016). The fast response from several agencies related to critical sectors such as district government, health personnel, and psychologists or psychiatric by using technology for risk detection and recovery due to future floods has been applied by developed countries. It plays a crucial role in minimising the impact of NCDs.

The most exposure by flooding in these selected articles is located in Asia. The research conducted by $\mathrm{Pan} \mathrm{Hu}$ stated that the Asian region is the most frequent flood, especially in China, India, Indonesia, and the Philippines ( $\mathrm{Hu} \mathrm{P}$, Zhang Q, Shi P, Chen B, 2018; Shao W, Xian S, Lin N, 2017). The region includes urban areas $(\mathrm{Hu} P$, Zhang $\mathrm{Q}$, Shi $\mathrm{P}$, Chen $\mathrm{B}$, 2018). In urban areas in Asia, especially in China, more floods occur because many underground infrastructures have been built (Chen Y, Zhou H, Zhang H, Du G, 2015). Another country, Pakistan, has implemented a Disaster risk Reduction Policy National ratified in 2013 as a comprehensive agenda for a rapid response to overcome the risk of a flood (Ashraf S, Luqman M, Iftikhar M, Ashraf I, 2017). On the other hand, many policies are conducted in the European region, America, and Australia to overcome or prevent floods. They plan the exclusive development in flood -prone zones to reduce the risk of damage (Mustafa A, Bruwier M, Archambeau P, Erpicum S, Pirotton M, Dewals B, 2018).

The strength of this research is the comprehensive analysis of each type of NCD for flood victims up to the meta -analysis stage. This study also provides a suggestion in the discussion to the government to prevent and immediately help flood victims to prevent the onset of NCDs, especially in urban areas.

\section{Conclusion}

This study concludes that various types of NCDs risk after being exposed to urban flooding could happen, and the risk of NCDs categories are mental illness from 19 selected articles $(0.53,95 \% \mathrm{CI}, 0.33-0.68)$, heart problems from 3 selected articles $(0.39,95 \%$ CI $-0.11-0.73)$, and respiratory problems from 3 selected articles $(0.53,95 \%$ CI, 0.02-0.82). Women and $\geq 40$-year-old people become the highest characteristics who are exposed to the flood and have the risk of these types of NCD. Selected articles that report more of this incident come from developed countries. Heterogeneous results $\left(\operatorname{tau}^{\wedge} 2 \mathrm{p}\right.$-value $\left.>0.05\right)$ and bias effects of publication (Egger test $\mathrm{p}$-value $>0.05$ ) in meta-analysis confirm that immediate rescue to the community with those characteristics should be implemented to prevent the onset of NCDs. Countries with good urban planning, technology to estimate the flood risk, and prevention programs of the urban flood are essential to prevent the significant onset of NCDs.

\section{Acknowledgement}

We thank Tri Dharma Performance Improvement Grant Program School of Strategic and Global Studies Universitas Indonesia No. PKS-0009/UN2.F13.D2/PPM.00.00/2021, which supported this article. The authors also would like to thank the National Library of the Republic of Indonesia, which provides digital library access needed to conduct this study.

\section{References}

Alderman, K., Turner, L. R., \& Tong, S. (2012). Floods and human health: a systematic review. Environment International, 47, $37-$ 47. 
Alderman, K., Turner, L. R., \& Tong, S. (2013). Assessment of the health impacts of the 2011 summer floods in Brisbane. Disaster Medicine and Public Health Preparedness. https:// doi.org/10.1017/dmp.2013.42

Amri MR, Yulianti G, Yunus R, Wiguna S, Adi AW, Ichwana AN, Randongkir RE, S. R. (2016). Risk Disaster in Indonesia. Badan Nas Penanggulangan Bencana Jakarta.

Ashraf S, Luqman M, Iftikhar M, Ashraf I, H. Z. (2017). Understanding Flood risk Management in Asia: Concepts and Challenges. In: Flood Risk Management. InTech.

Below R, Wirtz A, G.-S. D. (2009). Disaster category classification and peril terminology for operational purposes.

Bich TH, Quang LN, Ha LTT, Hanh TTD, G.-S. D. (2011). Impacts of flood on health: epidemiologic evidence from Hanoi, Vietnam. Glob Health Action, 4, 6356.

Birkett MA. (2011). The Trier Social Stress Test protocol for inducing psychological stress. JoVE (Journal Vis Exp), (56), e3238.

Chen Y, Zhou H, Zhang H, Du G, Z. J. (2015). Urban flood risk warning under rapid urbanization. Environ Res, 139, 3-10.

Cheng M, Wen S, jian Zhou H, Lian-fang B, Li J, X. L. (2013). Evaluation of headache and regional cerebral flood flow in patients with migraine. Clin Nucl Med, 38(11), 874-877.

Chung, M. C., Jalal, S., \& Khan, N. U. (2014). Posttraumatic stress disorder and psychiatric comorbidity following the 2010 flood in Pakistan: Exposure characteristics, cognitive distortions, and emotional suppression. Psychiatry (New York). https:// doi.org/10.1521/psyc.2014.77.3.289

Coughlin, S. S. (2011). Post-traumatic Stress Disorder and Cardiovascular Disease. The Open Cardiovascular Medicine Journal, 5, 164-170. https:// doi.org/10.2174/1874192401105010164

Dai W, Chen L, Tan H, Wang J, Lai Z, Kaminga AC, Li Y, L. A. (2016). Association between social support and recovery from post-traumatic stress disorder after flood: A 13-14 year followup study in Hunan, China Chronic Disease epidemiology. BMC Public Health, 16(1), 1-10.

Dai W, Kaminga AC, Tan H, Wang J, Lai Z, Wu X, L. A. (2017). Long-term psychological outcomes of flood survivors of hardhit areas of the 1998 Dongting Lake flood in China: Prevalence and risk factors. PLoS One, 12(2), 1-14.

Dai, W., Wang, J., Kaminga, A. C., Chen, L., Tan, H., Lai, Z., ... Liu, A. (2016). Predictors of recovery from post-traumatic stress disorder after the dongting lake flood in China: A 13-14 year follow-up study. BMC Psychiatry, 16(1), 1-10. https:// doi.org/10.1186/s12888-016-1097-x

Doocy S, Daniels A, Murray S, K. T. (2013). The Human Impact of Floods: a Historical Review of Events 1980-2009 and Systematic Literature Review. PLoS Curr.

Eiffert, S., Noibi, Y., Vesper, S., Downs, J., Fulk, F., Wallace, J., ... Winquist, A. (2016). A Citizen-Science Study Documents Environmental Exposures and Asthma Prevalence in Two Communities. Journal of Environmental and Public Health, 2016. https://doi.org/10.1155/2016/1962901

Equator Network. (2019). Preferred Reporting Items for Systematic Reviews and Meta-Analyses: The PRISMA Statement. Retrieved 17 July, 2020, from https://www.equator-network.org/reporting -guidelines/prisma/

Fernandez A, Black J, Jones M, Wilson L, Salvador-Carulla L, AstellBurt T, B. D. (2015). Flooding and mental health: A systematic mapping review. PLoS One, 10(4), 1-20.

Fewtrell L, K. D. (2008). An attempt to quantify the health impacts of flooding in the UK using an urban case study. Public Health, 122(5), 446-451.

Fontalba-Navas, A., Lucas-Borja, M. E., Gil-Aguilar, V., Arrebola, J. P., Pena-Andreu, J. M., \& Perez, J. (2017). Incidence and risk factors for post-traumatic stress disorder in a population affected by a severe flood. Public Health, 144, 96-102. https:// doi.org/10.1016/j.puhe.2016.12.015

French, C. E., Waite, T. D., Armstrong, B., Rubin, G. J., Beck, C. R.,
\& Oliver, I. (2019). Impact of repeat flooding on mental health and health-related quality of life: A cross-sectional analysis of the English National Study of Flooding and Health. BMJ Open. https://doi.org/10.1136/bmjopen-2019-031562

Graham H, White P, Cotton J, M. S. (2019). Flood-and WeatherDamaged Homes and Mental Health: An Analysis Using England's Mental Health Survey. Int $J$ Environ Res Public Health, 16(18), 2356.

Hanger S, Linnerooth-Bayer J, Surminski S, Nenciu-Posner C, Lorant A, Ionescu R, P. A. (2018). Insurance, Public Assistance, and Household Flood Risk Reduction: A Comparative Study of Austria, England, and Romania. Risk Anal, 38(4), 680-693.

Hu P, Zhang Q, Shi P, Chen B, F. J. (2018). Flood-induced mortality across the globe: Spatiotemporal pattern and influencing factors. Sci Total Environ, 647, 171-182.

Hu S, Tan H, Cofie R, Zhou J, Yang T, Tang X, L. A. (2015). Recovery from post-traumatic stress disorder after a flood in China: A 13-year follow-up and its prediction by degree of collective action. BMC Public Health.

Hu, S., Tan, H., Cofie, R., Zhou, J., Yang, T., Tang, X., \& Liu, A. (2015). Recovery from post-traumatic stress disorder after a flood in China: A 13-year follow-up and its prediction by degree of collective action. BMC Public Health, 15(1), 1-7. https://doi.org/10.1186/s12889-015-2009-6

Huang P, Tan H, Liu A, Feng S, C. M. (2010). Prediction of posttraumatic stress disorder among adults in flood district. BMC Public Health, 10, 2-9.

Husky MM, Alvarez V, Tapia G, Oprescu F, Navarro-mateu F, Kovess-masfety V, Ea LDP, B. U. De. (2020). Mental disorders and medical conditions associated with causing injury or death囚: A population-based study. Psychiatry Res, 287 (June, 112899.

Jahan S. (2015). Assessment of flood-related mental illness in Bangladesh. Queensland University of Technology.

Jimenez, A. M., Collins, T. W., \& Grineski, S. E. (2013). Intra-ethnic disparities in respiratory health problems among hispanic residents impacted by a flood. Journal of Asthma. https:// doi.org/10.3109/02770903.2013.786087

Kim Y Do, Tak YH, Park MH, K. B. (2020). Improvement of urban flood damage estimation using a high-resolution digital terrain. J Flood Risk Manag, 13(S1).

Laplante DP, Hart KJ, O'Hara MW, Brunet A, K. S. (2018). Prenatal maternal stress is associated with toddler cognitive functioning: The Iowa Flood Study. Early Hum Dev, 116 (Novem, 84-92. https://doi.org/https://doi.org/10.1016/ j.earlhumdev.2017.11.012

Li X, Huang X, Tan H, Liu A, Zhou J, Y. T. (2010). A study on the relationship between posttraumatic stress disorder in flood victim parents and children in Hunan, China. Aust $N Z J$ Psychiatry, 44(6), 543-550.

Lieberman-Cribbin W, Liu B, Schneider S, Schwartz R, T. E. (2017). Self-reported and FEMA flood exposure assessment after Hurricane Sandy: association with mental health outcomes. PLoS One, 12(1), e0170965.

Lieberman-Cribbin, W., Liu, B., Schneider, S., Schwartz, R., \& Taioli, E. (2017). Self-reported and FEMA flood exposure assessment after Hurricane Sandy: association with mental health outcomes. PLoS One, 12(1), e0170965.

Lin, C. Y., Chen, T. C., Dai, C. Y., Yu, M. L., Lu, P. L., Yen, J. H., \& Chen, Y. H. (2015). Serological investigation to identify risk factors for post-flood infectious diseases: A longitudinal survey among people displaced by Typhoon Morakot in Taiwan. BM) Open. https://doi.org/10.1136/bmjopen-2014-007008

Lowe D, Ebi KL, F. B. (2013). Factors increasing vulnerability to health effects before, during and after floods. Int $J$ Environ Res Public Health, 10(12), 7015-7067.

Luu C, von Meding J, M. M. (2019). Analysing Vietnam's national disaster loss database for flood risk assessment using multiple linear regression-TOPSIS. Int $J$ Disaster Risk Reduct, 40 (March), 101153. 
Maclean, J. C., Popovici, I., \& French, M. T. (2016). Are natural disasters in early childhood associated with mental health and substance use disorders as an adult? Social Science and Medicine, 151(2016), 78-91. https://doi.org/10.1016/ j.socscimed.2016.01.006

Martin, N. C., Felton, J. W., \& Cole, D. A. (2016). Predictors of Youths' Posttraumatic Stress Symptoms Following a Natural Disaster: The 2010 Nashville, Tennessee, Flood. Journal of Clinical Child and Adolescent Psychology. https:// doi.org/10.1080/15374416.2014.982279

Matsubara, C., Murakami, H., Imai, K., Mizoue, T., Akashi, H., Miyoshi, C., \& Nakasa, T. (2016). Prevalence and Risk Factors for Post-Traumatic Stress Reaction among Resident Survivors of the Tsunami That Followed the Great East Japan Earthquake, 11 March, 2011. Disaster Medicine and Public Health Preparedness. https://doi.org/10.1017/dmp.2016.18

Mazzoleni, M., Bacchi, B., Barontini, S., Di Baldassarre, G., Pilotti, M., \& Ranzi, R. (2014). Flooding hazard mapping in floodplain areas affected by piping breaches in the Po River, Italy. Journal of Hydrologic Engineering, 19(4), 717-731.

McCallum, I., Liu, W., See, L., Mechler, R., Keating, A., HochrainerStigler, S., ... Moorthy, I. (2016). Technologies to Support Community Flood Disaster Risk Reduction. International Journal of Disaster Risk Science, 7(2), 198-204. https:// doi.org/10.1007/s13753-016-0086-5

McLean, M. A., Cobham, V. E., Simcock, G., Kildea, S., \& King, S. (2019). Toddler temperament mediates the effect of prenatal maternal stress on childhood anxiety symptomatology: The QF2011 Queensland flood study. International Journal of Environmental Research and Public Health. https:// doi.org/10.3390/ijerph16111998

Miller JD, H. M. (2017). The impacts of urbanization and climate change on urban flooding and urban water quality: A review of the evidence concerning the United Kingdom. J Hydrol Reg Stud, 12, 345-362.

Mordeno, I. G., \& Cue, M. P. (2015). Examining the Latent Structure of Acute Stress Disorder Symptoms in FilipinoVictims of a Flashflood Disaster. Community Mental Health Journal, 51(5), 613-620. https://doi.org/10.1007/s10597-0159826-Z

Mulchandani, R., Smith, M., Armstrong, B., Beck, C. R., Oliver, I., Davidwaite, T., ... James Rubin, G. (2019). Effect of insurancerelated factors on the association between flooding and mental health outcomes. International Journal of Environmental Research and Public Health. https://doi.org/10.3390/ ijerph16071174

Munro, A., Kovats, R. S., Rubin, G. J., Waite, T. D., Bone, A., Armstrong, B., ... Oliver, I. (2017). Effect of evacuation and displacement on the association between flooding and mental health outcomes: a cross-sectional analysis of UK survey data. The Lancet Planetary Health, 1(4), e134-e141. https:// doi.org/10.1016/S2542-5196(17)30047-5

Mustafa A, Bruwier M, Archambeau P, Erpicum S, Pirotton M, Dewals B, T. J. (2018). Effects of spatial planning on future flood risks in urban environments. J Environ Manage, 225, 193-204.

Nagayoshi Y, Yumoto S, Sakaguchi K, Shudo C, Takino S, Hashiyama M, Kai Y, Kuroda Y, Kawano H, O. H. (2015). Heart attacks triggered by huge mudslides in mountain regions and severe flooding in inhabited areas. J Cardiol, 65(2), 117-120.

Nakamura, M., Tanaka, F., Nakajima, S., Honma, M., Sakai, T., Kawakami, M., ... Makita, S. (2012). Comparison of the incidence of acute decompensated heart failure before and after the major tsunami in northeast Japan. American Journal of Cardiology. https://doi.org/10.1016/j.amjcard.2012.08.020

Natgeo. (2018). Urban Area. Retrieved 1 April 2018, from https:// www.nationalgeographic.org/encyclopedia/urban-area/

O'Donovan A, Hughes BM, Slavich GM, Lynch L, Cronin M-T, O'Farrelly C, M. K. (2010). Clinical anxiety, cortisol and interleukin-6: Evidence for specificity in emotion- biology relationships. Brain Behav Immun, 24(7), 1074-1077.
Ohl CA, T. S. (2000). Flooding and human health. BMJ, 321(7270), 1167-1168.

Othman, A. Z., Dahlan, A., Borhani, S. N., \& Rusdi, H. (2016). Posttraumatic Stress Disorder and Quality of Life among Flood Disaster Victims. Procedia - Social and Behavioral Sciences, 234, 125-134. https://doi.org/10.1016/j.sbspro.2016.10.227

Paterson DL, Wright H, H. P. (2018). Health Risks of Flood Disasters. Clin Infect Dis, 67(9), 1450-1454.

Pattison I, L. S. (2012). The link between land-use management and fluvial flood risk: A chaotic conception? Prog Phys Geogr, 36 (1), 72-92.

Poku-boansi M, Amoako C, Owusu-ansah JK, B. P. (2020). What the state does but fails: Exploring smart options for urban flood risk management in informal Accra, Ghana. City Environ Interact, 5, 100038.

Puechlong, C., Weiss, K., Le Vigouroux, S., \& Charbonnier, E. (2020). Role of personality traits and cognitive emotion regulation strategies in symptoms of post-traumatic stress disorder among flood victims. International Journal of Disaster Risk Reduction, 50, 101688. https://doi.org/10.1016/ j.ijdrr.2020.101688

Reifels, L., Bassilios, B., Spittal, M. J., King, K., Fletcher, J., \& Pirkis, J. (2015). Patterns and predictors of primary mental health service use following bushfire and flood disasters. Disaster Medicine and Public Health Preparedness, 9(3), 275-282. https://doi.org/10.1017/dmp.2015.23

Rossati A. (2017). Global Warming and Its Health Impact. Int J Occup Environ Med, 8(1), 7-20.

Ryan B, Franklin RC, Burkle FM, Aitken P, Smith E, Watt K, L. P. (2015). Identifying and Describing the Impact of Cyclone, Storm, and Flood Related Disasters on Treatment Management, Care and Exacerbations of Non-communicable Diseases and the Implications for Public Health. PLoS Curr.

Ryan BJ, Franklin RC, Burkle FM, Smith EC, Aitken P, L. P. (2019) Determining key influences on patient ability to successfully manage non-communicable disease after natural disaster. Prehosp Disaster Med, 43(3), 241-250.

Satoh J, Yokono K, Ando R, Asakura T, Hanzawa K, Ishigaki Y, Kadowaki T, Kasuga M, Katagiri H, K. (2019). Diabetes care providers' manual for disaster diabetes care. Diabetol Int, 10(3), 153-179.

Saulnier DD, Brolin Ribacke K, von S. J. (2017). No Calm After the Storm: A Systematic Review of Human Health Following Flood and Storm Disasters. Prehosp Disaster Med, 32(5), 568-579.

Saulnier DD, Hanson C, Ir P, Mölsted Alvesson H, von S. J. (2018). The Effect of Seasonal Floods on Health: Analysis of Six Years of National Health Data and Flood Maps. Int J Environ Res Public Health, 15(4).

Shao W, Xian S, Lin N, S. M. (2017). A sequential model to link contextual risk, perception and public support for flood adaptation policy. Water Res, 122, 216-225.

Sofia, G., Roder, G., Dalla Fontana, G., \& Tarolli, P. (2017). Flood dynamics in urbanised landscapes: 100 years of climate and humans' interaction. Scientific Reports, 7, 40527.

Stanaway JD, Afshin A, Gakidou E, Lim SS, Abate D, Abate KH, Abbafati C, Abbasi N, ... Murray CJL. (2018). Global, regional, and national comparative risk assessment of 84 behavioural, environmental and occupational, and metabolic risks or clusters of risks for 195 countries and territories, 1990-2017: A systematic analysis for the Global Burden of Disease Stu. Lancet, 392(10159), 1923-1994.

van den Bosch, M., \& Sang, A. O. (2017). Urban natural environments as nature-based solutions for improved public health-A systematic review of reviews. Environmental Research, 158, 373-384.

Van Voorst, R. (2016). Formal and informal flood governance in Jakarta, Indonesia. Habitat International, 52, 5-10.

Vanasse, A., Cohen, A., Courteau, J., Bergeron, P., Dault, R., Gosselin, P., ... Chebana, F. (2016). Association between floods and acute cardiovascular diseases: A population-based cohort 
study using a geographic information system approach. International Journal of Environmental Research and Public Health, 13(2), 1-12. https://doi.org/10.3390/ijerph13020168

Waite, T. D., Chaintarli, K., Beck, C. R., Bone, A., Amlôt, R., Kovats, S., ... Oliver, I. (2017). The English national cohort study of flooding and health: cross-sectional analysis of mental health outcomes at year one. BMC Public Health. https:// doi.org/10.1186/s12889-016-4000-2

Walker JT. (2018). The influence of climate change on waterborne disease and Legionella: a review. Perspect Public Health, 138(5), 282-286.

Wei, Q., Zhang, X., Yi, W., Pan, R., Gao, J., Duan, J., ... Su, H. (2020). Association between floods and hospital admissions for schizophrenia in Hefei, China: The lag effects of degrees of floods and time variation. Science of the Total Environment, 698, 134179. https://doi.org/10.1016/j.scitotenv.2019.134179

Weiss K. (2020). Role of personality traits and cognitive emotion regulation strategies in symptoms of post-traumatic stress disorder among flood victims. Int $J$ Disaster Risk Reduct, 101688.

Wesli W, Sirojuzilam S, Matondang AR, L. S. (2013). The Effect of Land Use and Community Participation on Flood Control at North Aceh District. Indones J Geogr, 45(2), 171-186.

WHO. (2011). The Worldwide Rise of Chronic Noncommunicable Diseases: A Slow-Motion Catastrophe.

Wing OEJ, Bates PD, Smith AM, Sampson CC, Johnson KA, Fargione J, M. P. (2018). Estimates of present and future flood risk in the conterminous United States. Environ Res Lett, 13(3), 34023.

Wolfram F, L. T. (2019). A simulation study of the HIFU ablation process on lung Tumours, showing consequences of atypical acoustic properties in flooded lungs. $Z$ Med Phys, 29(1), 49-58.

Yoda, T., Yokoyama, K., Suzuki, H., \& Hirao, T. (2017). Relationship Between Long-term Flooding and Serious Mental Illness After the 2011 Flood in Thailand. Disaster Medicine and Public Health Preparedness, 11(3), 300-304. https:// doi.org/10.1017/dmp.2016.148

Zeligman, M., McElroy-Heltzel, S. E., Davis, E. B., Dispenza, F., Davis, D. E., \& DeBlaere, C. (2019). Posttraumatic Growth and Trauma in Flood Survivors: Contributions of Attitudes Toward God. Journal of Mental Health Counseling. https:// doi.org/10.17744/mehc.41.2.03 